Comparative Evaluation of in - vitro Anthelmintic Activity of Sap, Fruit bulb, and Root of Borassus flabellifer

Thuvaragan.S ${ }^{1}$, H.M.P.M. Jeyasinghe ${ }^{2}$, Murugananthan. $\mathrm{A}^{3}$

${ }^{I}$ Department of Pharmacy, Faculty of Allied Health Sciences, University of Jaffna, Sri Lanka, sthuvaragan@univ.jfn.ac.lk

${ }^{2}$ Pharmacist, Regional Director Health Services, Gampaha, Sri Lanka, pasindumaneeshe89@gmail.com

${ }^{3}$ Department of Parasitology, Faculty of Medicine, University of Jaffna, Sri Lanka, ananthan10@gmail.com 


\title{
COMPARATIVE EVALUATION OF IN - VITRO ANTHELMINTIC ACTIVITY OF SAP, FRUIT BULB, AND ROOT OF Borassus flabellifer
}

\begin{abstract}
Helminth infections are major health problems, especially in developing countries with warm and humid environments. Limited synthetic drugs are available for treating helminth infections, and some of them showed resistance to helminths. Phytoconstituents can be used to develop cheap and effective anthelminthic drugs. Borassus flabellifer has been used in traditional medicine, in addition to consuming as food. This study was designed to evaluate the comparative in vitro anthelmintic activities of aqueous and methanol extracts of root, fruit pulp, and sap of Borassus flabellifer using two different concentrations $(50$ and $100 \mathrm{mg} / \mathrm{mL})$. Adult earthworms, Eisenia fetida was used to evaluate the in-vitro anthelmintic activity. In-vitro anthelmintic activity was evaluated by determining times of paralysis and the death of worms. The anthelminthic activity of extracts was compared with mebendazole, and earthworm saline was used as a control. ANOVA followed by Dunnett's multiple comparison test was used to compare the activities of extracts with mebendazole. All extracts showed concentrations dependent activity. All extracts except aqueous extract of roots of Borassus flabellifer showed statistically significant in-vitro anthelminthic activity. Further studies are needed to isolate and evaluate the active components from the extracts of Borassus flabellifer.
\end{abstract}

Keywords: Borassus flabellifer, Sap, Root, Fruit bulb, Extracts, Anthelmintic activity

\section{Introduction}

In developing countries, parasitic intestinal infections are a major health problem. More than one billion people are estimated to be infected with helminth infection in developing countries. (Williams, A.R et al., 2014) An estimated 4.7 billion people worldwide live in regions with a high potential for exposure to soil-transmitted helminths (Salmon, M et al., 2018).

Helminth infections cause several clinical infestations such as malnutrition, intestinal and biliary obstruction, dysentery, and anemia. Risk of populations by helminth infections include preschool and school-age children and women of reproductive age (WHO, 2010). An area that has poor sanitation is also more at risk for soiltransmitted helminth infections. Children of school age of 5 to 14 years in low-income countries' helminth infections account for $12 \%$ of the total disease burden (Awasthi S et al., 2013).

Limited drugs are available in the eradication of helminth infections. The repeated occurrence of these helminth infections results in frequent usage of anthelmintic drugs. It results in drug resistance (Fouche G et al., 2016a) and increased cost of treatment. Searching for new drugs for helminth infections is important to control the disease as it is widely distributed in the human population (Fouche G et al., 2016b). In the last three decades, no new anthelmintic drugs have been introduced for human usage (Panic et al., 2014).

According to WHO, $80 \%$ of the world's population depends on traditional medicines for their healthcare needs. Traditionally many herbals are used in helminth infections. Some compounds isolated from medicinal plants have shown anthelminthic activity (Liu, Maoxuan, et al., 2020). Herbals and their secondary metabolites may be used effectively for parasite control. Screening of traditionally used anthelmintic plants' pharmacological activity will lead to new drug candidates with lesser side effects (Rafi KP et al., 2011). These plants can be used as phytotherapeutics or food supplements in the management of helminth infections. Consuming plants with anthelmintic activity as food supplements may reduce the incidence of helminth infections. 
Borassus flabellifer belongs to Arecaceae, is growing widely in tropical countries. It is cultivated in many tropical countries like India, Bangladesh, Burma, Sri Lanka, Malaysia, and tropical Africa (Aval A et al., 1995). Different parts of plants are used medicinally as well as food supplements. Saps obtained from inflorescence were used as a refreshing drink. Some traditional practitioners used sap for the treatment of intestinal worm infections in Sri Lanka. Fruits are sweet and consumed by people in Asian countries. The root of palmyrah also was consumed by people, and it is powdered to make different foods. In the present study, different solvent extracts of sap, root, and fruit bulb are screened for in vitro anthelmintic activity.

\section{Materials}

Drug: Mebendazole

Chemicals: Methanol, Distilled water, Sodium chloride $(\mathrm{NaCl})$, Potassium chloride $(\mathrm{KCl})$, Calcium chloride $\left(\mathrm{CaCl}_{2}\right)$, Sodium bicarbonate $\left(\mathrm{NaHCO}_{3}\right)$, Dimethyl sulfoxide (DMSO)

\section{Methods}

\section{Preparation of Extracts}

Aqueous and Methanol extracts were prepared using sun-dried fruit pulp (Pinnatu), roots (Odial / Kottakilangu), and sap (toddy palm). The roots and "Pinnatu" were collected and air-dried in the shade at room temperature. Methanol and aqueous extracts of fruit bulb and root were prepared using the soxhlet apparatus and concentrated using a rotary evaporator. Methanol extract of toddy was prepared by evaporating it using a rotary evaporator, and the resultant residue was dissolved in methanol and filtered to get methanol extract of toddy.

\section{Experimental worms}

The adult earthworms, Eisenia fetida, known under various common names such as redworm, brandling worm, panfish worm, trout worm, tiger worm, red wiggler worm, red Californian earthworm, etc., resemble the intestinal roundworms parasites of humans in their anatomical and physiological characters were used for this study (Kainsa S. et al.,2012). The above worms were collected from "Green Visva Lanka Farm Developers, Thoddilady, Villavily, Chankanai." The collected worms were washed initially with tap water followed by earthworm saline to remove the soil particles and debris.

\section{Sample preparation}

Samples of aqueous extracts were prepared by dissolving $500 \mathrm{mg}$ and $1000 \mathrm{mg}$ of crude extract in $1 \mathrm{ml}$ of DMSO and make up the volume with saline up to $10 \mathrm{~mL}$ with saline solution. Final concentration of extracts was obtained as $50 \mathrm{mg} / \mathrm{mL}$ and $100 \mathrm{mg} / \mathrm{mL}$ respectively. Earthworm saline was used as a control, and mebendazole was used as the standard drug for this study.

\section{Evaluation of anthelmintic activity}

The anthelmintic activity was performed on the adult Indian earthworm Eisenia fetida. The in-vitro studies were performed according to the previous studies (Prasad Govind Rao Jamkhande et al., 2014). The worms were divided into 24 groups containing two earthworms of approximately equal size and weight. Worms were placed in Petri dishes containing different concentrations of the extracts separately. $10 \mathrm{~mL}$ suspensions of aqueous and methanolic extracts were used as test samples. Mebendazole $(20 \mathrm{mg} / \mathrm{mL})$ with $2 \%$ Gum Acacia in saline was used as a reference, and the earthworm saline was used as the control group. 
Two worms were placed in each group, and they were observed for their spontaneous motility and evoked responses. Time of death was noted when the worms showed zero response to the stimuli even after performing the prick test and when dropped in warm water $\left(50^{\circ} \mathrm{C}\right)$ followed with fading away of their body color (Ajaiyeoba E O et al., 2001). All experiments were done in triplicate.

\section{Statistical analysis}

Statistical analysis was conducted with SPSS version 25. All values were presented as mean with standard deviation. Comparison of anthelmintic activity of extracts with reference drug in terms of paralyzed and death times were assessed by one-way- ANOVA followed by Dunnett test. The values of P less than 0.05 were considered a statistically significant difference.

\section{Results and Discussion}

The effects of different concentrations of aqueous and methanolic extracts of the products derived from Borassus flabellifer plant and mebendazole on adult earthworms (Eisenia fetida) were depicted in Table 1.

Extracts of sap, root, and fruit bulb of Borassus flabellifer showed anthelmintic activity. A dose-dependent onset of paralysis and mortality was observed in the earthworms treated with the extracts. They were compared with mebendazole as the reference drug.

Figure 1 and 2 shows paralyzed and death times of different extracts of Based on the results, paralyzed and death times is more in the methanol extracts than aqueous extracts except in the sap extracts. This may be due to more number of active phytoconstituents and their higher proportion present in the methanol extracts than aqueous extract. Aqueous extract of sap showed shorter paralysis and death times than the methanol extract. The better activity of sap extracts may be due to alkaloids and steroids present in a higher proportion than other extracts.

Table 1: Paralyzed and death times of different extracts with $P$ values

\begin{tabular}{|c|c|c|c|c|c|c|}
\hline Plant parts & Extracts & $\begin{array}{l}\text { Concentration } \\
(\mathrm{mg} / \mathrm{mL})\end{array}$ & $\begin{array}{l}\text { Paralyzed } \\
\text { time (mins) }\end{array}$ & P value & $\begin{array}{l}\text { Death time } \\
\text { (mins) }\end{array}$ & $\begin{array}{l}P \\
\text { value }\end{array}$ \\
\hline \multirow[t]{4}{*}{ Sap } & \multirow{2}{*}{$\begin{array}{l}\text { Methanol } \\
\text { extract }\end{array}$} & 50 & $19.86 \pm 0.65$ & 0.00 & $25.26 \pm 0.28$ & 0.00 \\
\hline & & 100 & $8.9 \pm 0.00$ & 0.00 & $9.50 \pm 0.00$ & 0.005 \\
\hline & \multirow{2}{*}{$\begin{array}{l}\text { Aqueous } \\
\text { extract }\end{array}$} & 50 & $11.10 \pm 0.16$ & 0.00 & $14.00 \pm 0.16$ & 0.00 \\
\hline & & 100 & $5.43 \pm 0.09$ & 0.031 & $7.00 \pm 0.00$ & 0.006 \\
\hline \multirow[t]{4}{*}{ Fruit bulb } & \multirow{2}{*}{$\begin{array}{l}\text { Methanol } \\
\text { extract }\end{array}$} & 50 & $35.13 \pm 0.04$ & 0.00 & $38.70 \pm 0.28$ & 0.00 \\
\hline & & 100 & $7.36 \pm 0.12$ & 0.00 & $8.30 \pm 0.04$ & 0.680 \\
\hline & \multirow{2}{*}{$\begin{array}{l}\text { Aqueous } \\
\text { extract }\end{array}$} & 50 & $81.5 \pm 0.57$ & 0.00 & $108.3 \pm 0.80$ & 0.00 \\
\hline & & 100 & $14.50 \pm 0.14$ & 0.00 & $18.23 \pm 0.38$ & 0.00 \\
\hline \multirow[t]{2}{*}{ Root } & Methanol & 50 & $6.56 \pm 0.17$ & 0.002 & $11.66 \pm 0.175$ & 0.00 \\
\hline & & 100 & $4.50 \pm 0.08$ & 0.997 & $5.43 \pm 0.09$ & 0.00 \\
\hline
\end{tabular}


Thuvaragan.S / Comparative Evaluation of in - vitro Anthelmintic Activity of Sap, Fruit bulb, and Root of Borassus flabellifer

\begin{tabular}{lccccc}
\hline & $\begin{array}{l}\text { Aqueous } \\
\text { extract }\end{array}$ & 50 & - & - & Survived \\
\cline { 3 - 6 } & & 100 & - & - & Survived \\
& & & & & \\
& & & & & \\
\hline Mebendazole & 20 & $4.33 \pm 0.33$ & - & $8.33 \pm 0.33$ & - \\
\hline $\begin{array}{l}\text { Control } \\
\text { (Normal }\end{array}$ & - & - & & Survived & - \\
Saline) & & & & \\
\hline
\end{tabular}

Methanol extract of root showed the death for earthworms even in its minimum concentration $(50 \mathrm{mg} / \mathrm{mL})$. However, the aqueous root extract did not show any paralysis or death for earthworms even in its maximum concentration $(100 \mathrm{mg} / \mathrm{mL})$.

According to a literature survey on phytochemical screenings, the toddy of Borassus flabellifer is positive for alkaloids and steroids such as Borassosides and Dioscin (Tribuvan Singh et al., 2016). The aqueous and methanolic extracts of raw palmyrah fruit pulp (RPFP) and thermally processed palmyrah fruit pulp (PPFP) of the Borassus flabellifer plant are positive for alkaloids, flavonoids, terpenoids, glycosides, saponins, phenolics, tannins, steroids, and sterols (Saranya, P. and Poongodi Vijayakumar, T., 2016). The root of the Borassus flabellifer plant is positive for tannins, phenols, steroids, flavonoids, saponins, and alkaloids (Saravanan, C et al.,2012) (Chayanika Sahni et al., 2014).

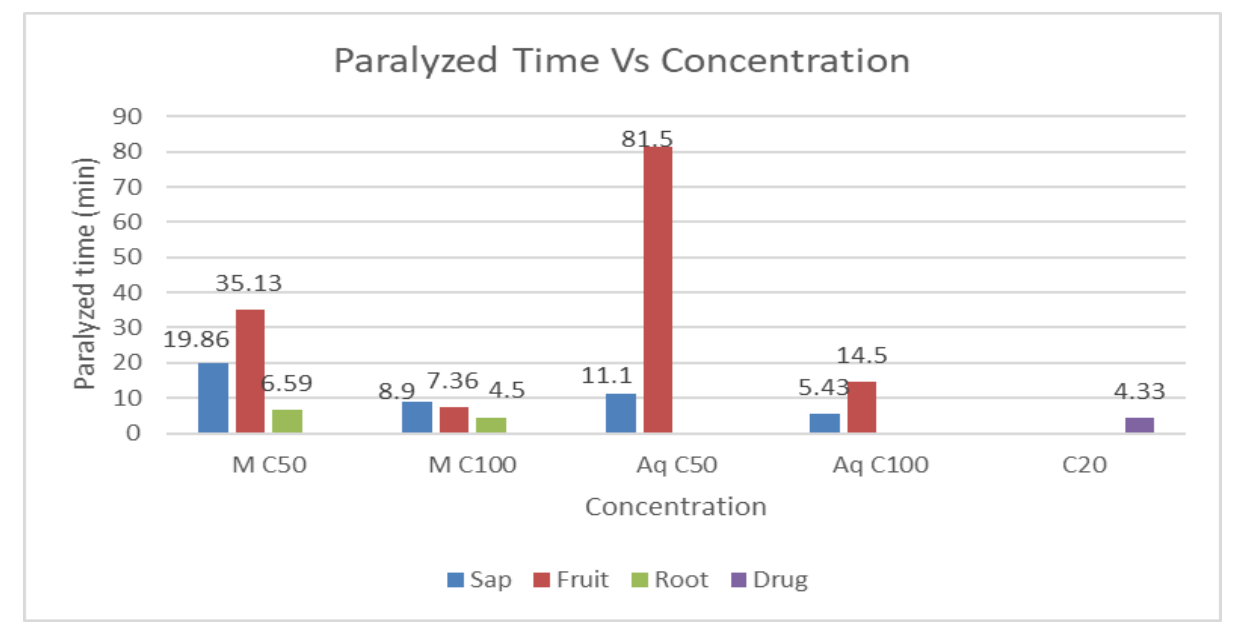

Figure 1: Paralyzed time of different extracts 


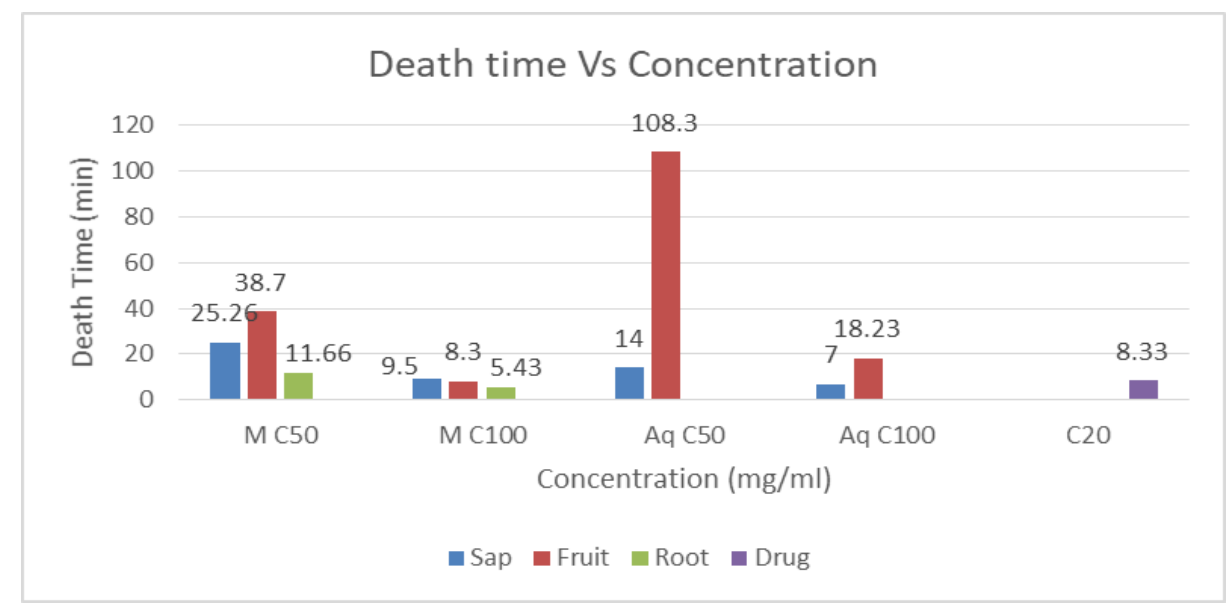

Figure 2: Death time of different extracts

Several phytochemicals have anthelmintic activities. Extracts of the plant contain several phytoconstituents, and the plant's anthelmintic activity may be due to these compounds' synergistic effect. Phytocompounds that showed anthelminthic activity include saponins, alkaloids, polyphenols, tannins, etc. Different phytoconstituents act as anthelmintic agents in different mechanisms (Manke et al., 2014). These compounds are present in Borassus flabellifer and could be responsible for the anthelmintic activity.

According to the ANOVA test, all plant extracts at the 50 and $100 \mathrm{mg} / \mathrm{mL}$ concentrations showed a statistically significant difference in the anthelminthic activity except for two extracts. Methanol extract of root at $100 \mathrm{mg} / \mathrm{mL}$ and methanol extract of fruit bulb at $100 \mathrm{mg} / \mathrm{mL}$ did not show a statistically significant difference. Extracts such as aqueous sap extract at $100 \mathrm{mg} / \mathrm{mL}$, methanol extract of fruit bulb at $100 \mathrm{mg} / \mathrm{mL}$, and methanol extract of root at $100 \mathrm{mg} / \mathrm{mL}$ showed comparable activity to the reference drug.

Further in-vitro studies are needed to confirm the pharmacological activity of these extracts. Phytochemical screening and isolation of actives present in the extracts should be further conducted. Also, the precise mechanism of anthelmintic activity needs to be found out.

\section{Conclusion}

Extracts of sap, root, and fruit bulb of Borassus flabellifer showed good anthelmintic activity against adult earthworms, Eisenia fetida. Isolation of active principles and screening of their anthelminthic activity may explore new drug candidates.

\section{Acknowledgment}

The authors are grateful to all academic and non-academic staff of Faculty of Allied Health Sciences and Faculty of Medicine, University of Jaffna, Sri Lanka for their extended support to complete this study. 
Thuvaragan.S / Comparative Evaluation of in - vitro Anthelmintic Activity of Sap, Fruit bulb, and Root of Borassus flabellifer

\section{References}

Ajaiyeoba E O, Onocha P A, Olarenwaju O T; In-vitro anthelmintic properties of Buchholzia coriaceae and Gynandropsis gynandra extract. Pharm Biol. 2001; 39:217-220.

Awal A, Haq QN, Quader MA, Ahmed M. Structural study of a polysaccharide from the seeds of Borassus flabellifer Linn. Carbohydr Res 1995; 277: 189-195.

Awasthi, S., Bundy, D. A., \& Savioli, L. (2003). Helminthic infections. BMJ (Clinical research ed.), 327(7412), 431-433. doi:10.1136/BMJ.327.7412.431

Chayanika Sahni et al. Screening of Nutritional, Phytochemical, Antioxidant and Antibacterial activity of the roots of Borassus flabellifer (Asian Palmyra Palm) Journal of Pharmacognosy and Phytochemistry (2014) 2014; 3(4): $58-68$

Fouche, G., et al., (2016). Anthelmintic activity of acetone extracts from South African plants used on egg hatching of Haemonchus contortus. The Onderstepoort journal of veterinary research, 83(1), e1-e7. doi:10.4102/ojvr.v83i1.1164

Kansa, S., Kumar, P. and Dahiya, R.S., 2012. Investigation of in vitro anthelmintic activity of Cassia auriculata leaves. J. Nat. Prod. Plant Resour, 2(4), pp.460-4.

Liu, M., Panda, S. K., \& Luyten, W. (2020). Plant-Based Natural Products for the Discovery and Development of Novel Anthelmintics against Nematodes. Biomolecules, 10(3), 426. https://doi.org/10.3390/biom10030426

Manke, M., Dhawale, S., \& Jamkhande, P.G. (2015). Helminthiasis and medicinal plants: a review. Asian Pacific Journal of Tropical Disease, 5, 175-180.

Panic G, Duthaler U, Speich B, Keiser J. Repurposing drugs for the treatment and control of helminth infections. Int J Parasitol Drugs Drug Resist. 2014 Jul 30;4(3):185-200. DOI: 10.1016/j.ijpddr.2014.07.002

Prasad Govindrao Jamkhande, P.G., Suryawanshi, V.A., Wattamwar, A.S., and Barde, S.R., 2014. In vitro anthelmintic efficacy of Borassus flabellifer Linn. (Palmae) against Pheretima Posthuma. Asian Pacific Journal of Tropical Disease, 4, pp.S199-S203.

Rafi KP, Karthikeyan M, Kannan M, Rajasekar S. Anthelmintic activity of Nerium oleander flower extract in Indian adult earthworm. J Nat Prod Plant Resour 2011; 1(4): 40-46.

Salmon, M., Salmon, C., Masuda, M., Salumu, J. M., Bozzi, C., Nieburg, P., ... Cappello, M. (2018). Albendazole Treatment Improves Work Capacity in Women Smallholder Farmers Infected with Hookworm: A Double-Blind Randomized Control Trial. The American journal of tropical medicine and hygiene, 98(5), 14191426. doi:10.4269/ajtmh.17-0403

Saranya, P. and Poongodi Vijayakumar, T., Preliminary phytochemical screening of raw and thermally processed palmyra palm (Borassus flabellifer Linn.) fruit pulp. Journal of Innovations in Pharmaceuticals and Biological Sciences. 3 (1), 186-193 2016

Saravanan, C., Priya, B., Bradley, A.S., and Sundaram, U., 2012. Preliminary phytochemical screening of antibacterial activity of palmyra palm (Borassus flabellifer) root extract. International Journal of Pharmaceutical Sciences and Research, 3(11), p.4489.

Tribhuvan Singh et al., 2015. Comparative study of in vitro anthelmintic activity of sap of Borassus flabellifer. World Journal of Pharmacy and Pharmaceutical Sciences. 5(1) p 701-706. 
Thuvaragan.S / Comparative Evaluation of in - vitro Anthelmintic Activity of Sap, Fruit bulb, and Root of Borassus flabellifer

Williams, A.R., Ropiak, H.M., Fryganas, C., et al. Assessment of the anthelmintic activity of medicinal plant extracts and purified condensed tannins against free-living and parasitic stages of Oesophagostomum dentatum Parasites Vectors (2014) 7: 518. https://doi.org/10.1186/s13071-014-0518-2

World Health Organization. First WHO Report on Neglected Tropical Diseases: working to overcome the impact of neglected tropical diseases. Geneva: World Health Organization, 2010 